Check for updates

Cite this: Phys. Chem. Chem. Phys., 2018, 20, 28346

DOI: $10.1039 / c 8 c p 91863 e$

rsc.li/pccp

\section{Correction: Developing force fields when experimental data is sparse: AMBER/ GAFF-compatible parameters for inorganic and alkyl oxoanions}

\author{
Sadra Kashefolgheta (D) and Ana Vila Verde (D) *
}

Correction for 'Developing force fields when experimental data is sparse: AMBER/GAFF-compatible parameters for inorganic and alkyl oxoanions' by Sadra Kashefolgheta et al., Phys. Chem. Chem. Phys., 2017, 19, 20593-20607.

Table 4: In the second order perturbation theory analysis of Fock matrix in NBO basis presented in the published version of Table 4, obtained with Gaussian NBO Version 3.1, the stabilization energies for Donor $\left(\mathrm{BD}^{*} \mathrm{~S}-\mathrm{O}\right)$ Acceptor $\left(\mathrm{BD}^{*} \mathrm{H}-\mathrm{N}\right)$ and Donor $\left(\mathrm{BD}^{*} \mathrm{P}-\mathrm{O}\right)^{1}$ Acceptor $\left(\mathrm{BD}^{*} \mathrm{H}-\mathrm{N}\right)$ should not be considered. Those energies were calculated with expression $E(2)$, which is not valid because the $\mathrm{BD}^{*}$ orbitals have very similar energies: when such energy degeneracy occurs, it invalidates the perturbative analysis and the small value of the denominator results in excessively high estimates of the stabilization energy. We communicated with the developers of the NBO6 program, who clarified that the only interactions that matter are those involving $\mathrm{CR}$, LP, and $\mathrm{BD}$ donors. $\mathrm{BD}^{*}$ donors should be ignored as is already done in newer versions of $\mathrm{NBO}$, where second order perturbation analysis is performed for $\mathrm{CR}$, $\mathrm{LP}$, and $\mathrm{BD}$ donors only. Therefore we removed the entries for $\mathrm{BD}^{*}$ donors from the revised version of Table 4 (below). We thank an anonymous reviewer for drawing our attention to this issue.

We also modified the contributions to the stabilization energy arising from the interactions between Donor $(\operatorname{LP}(1-3) \mathrm{O})$ and Acceptor $\left(\mathrm{BD}^{*} \mathrm{H}-\mathrm{N}\right)$ in orientation I: whereas previously we had calculated these contributions ${ }^{2}$ by considering the lone pair with largest stabilization energy, now we consider each of the three lone pairs of oxygen as a donor, and the anti-bondings of nitrogen with each of the hydrogens as acceptors, as described in the footnote of the revised version of Table 4, to account for all the stabilization contributions. To allow readers to re-evaluate any quantities of interest from scratch, we now provide the full output from the NBO analysis we performed (NBO_output.tar) as ESI.

The changes we now submit in the revised version of Table 4 alter the values of the stabilization energies in orientation I, but do not alter the main conclusions to be drawn from them: the new values remain very high. Because high stabilization energies are not expected between two ions in solution, this orientation should not be used to develop ion parameters for the solution phase following our methodology as we indicated in the paper.

Fig. 8 and Table S5 (ESI): In this figure and table, the correct formula for the sodium acetate salt is $\mathrm{NaCH}_{3} \mathrm{COO}$ instead of $\mathrm{NaCH}_{3} \mathrm{COOH}$. 
Table 4 Second order perturbation theory analysis of Fock matrix in NBO basis for anion-cation pairs

\begin{tabular}{|c|c|c|c|}
\hline Ion-pair & Donor $(i)$ & Acceptor $(j)$ & $E(2)^{d, e}\left(R_{\mathrm{m}}\right) \mathrm{kcal} \mathrm{mol}^{-1}$ \\
\hline $\begin{array}{l}\text { Anion- } \mathrm{Na}^{+} \\
\mathrm{CH}_{3} \mathrm{SO}_{3}{ }^{-} \cdots \mathrm{Na}^{+} \\
\mathrm{CH}_{3} \mathrm{SO}_{4}{ }^{-} \cdots \mathrm{Na}^{+} \\
\mathrm{CH}_{3} \mathrm{COO}^{-} \cdots \mathrm{Na}^{+} \\
\mathrm{H}_{2} \mathrm{PO}_{4}{ }^{-} \cdots \mathrm{Na}^{+} \\
\left(\mathrm{CH}_{3}\right)_{2} \mathrm{PO}_{4}^{-} \cdot \mathrm{Na}^{+} \\
\mathrm{SO}_{4}{ }^{2} \cdot \cdots \mathrm{Na}^{+} \\
\mathrm{CH}_{3} \mathrm{PO}_{4}{ }^{2-} \cdots \mathrm{Na}^{+}\end{array}$ & $\begin{array}{l}\mathrm{LP}(1-3) \mathrm{O} \\
\mathrm{LP}(1-3) \mathrm{O}^{a} \\
\mathrm{LP}(1-3) \mathrm{O} \\
\mathrm{LP}(1-3) \mathrm{O}^{a} \\
\mathrm{LP}(1-3) \mathrm{O}^{a} \\
\mathrm{LP}(1-3) \mathrm{O} \\
\mathrm{LP}(1-3) \mathrm{O}^{a}\end{array}$ & $\begin{array}{l}\mathrm{LP}^{*}(1-3) \mathrm{Na} \\
\mathrm{LP}(1-3) \mathrm{Na} \\
\mathrm{LP} P^{*}(1-3) \mathrm{Na} \\
\mathrm{LP} P^{*}(1-3) \mathrm{Na} \\
\mathrm{LP}(1-3) \mathrm{Na} \\
\mathrm{LP}^{*}(1-3) \mathrm{Na} \\
\mathrm{LP}^{*}(1-3) \mathrm{Na}\end{array}$ & $\begin{array}{r}7.5^{b} \\
6.5^{b} \\
10.0^{b} \\
7.0^{b} \\
7.0^{b} \\
11.5^{b} \\
11.0^{b}\end{array}$ \\
\hline
\end{tabular}

$\mathrm{LP}=$ lone pair. $\mathrm{LP}^{*}=$ unfilled valence-shell. $\mathrm{BD}^{*}=$ valence anti-bonding. ${ }^{a}$ There are two different oxygens in this molecule as described in Fig. $\mathrm{S} 1$ of the ESI, please look at the output files to see the orientations we examined. ${ }^{b}$ Sum of all stabilization energies, considering each of the three lone pairs of oxygen, $\mathrm{LP}(1-3) \mathrm{O}$, as a donor and each of the three unfilled valence-shell of $\mathrm{Na}^{+}, \mathrm{LP}^{*}(1-3) \mathrm{Na}$, as an acceptor. ${ }^{c}$ Sum of all stabilization energies, considering each of the three lone pairs of oxygen, LP(1-3)O, as a donor and the anti-bondings of nitrogen with each of $\mathrm{H} 1$, $\mathrm{H} 2$ and $\mathrm{H} 3$, $\mathrm{BD}^{*} \mathrm{~N}-\mathrm{H}(1-3)$, as an acceptor. ${ }^{d}$ Stabilization energy $E(2)$ estimated as $E(2)=\Delta E_{i j}=q_{i} \frac{F(i, j)^{2}}{\varepsilon_{j}-\varepsilon_{i}}$, where $q_{i}$ is the donor orbital occupancy, $\varepsilon_{i}, \varepsilon_{j}$ are diagonal elements (orbital energies) and $F(i, j)$ is the off-diagonal element of NBO Fock matrix. ${ }^{3}{ }^{e}$ Values are rounded up to the next half kcal mol ${ }^{-1}$.

The Royal Society of Chemistry apologises for these errors and any consequent inconvenience to authors and readers.

\section{References}

1 This entry was incorrectly written as Donor $\left(\mathrm{BD}^{*} \mathrm{~S}-\mathrm{O}\right)$ instead of Donor $\left(\mathrm{BD}^{*} \mathrm{P}-\mathrm{O}\right)$ in the published version of Table 4.

2 Denoted as Donor(LP(2)O) in the published version of Table 4.

3 E. D. Glendening, J. K. Badenhoop, A. E. Reed, J. E. Carpenter, J. A. Bohmann, C. M. Morales, C. R. Landis and F. Weinhold, NBO 6.0., Theoretical and Chemistry Institute, University of Wisconsin, Madison, 2013. 